\title{
Impact of Medical Technology on Expansion in Healthcare Expenses
}

\author{
Shakir Khan (Corresponding Author), Dr. Mohamed Fahad AlAjmi
}

\begin{abstract}
- the impact of medical technology on expansion in health care expenses has long been a subject of essential interest, mainly in the context of long-term outcrops of health spending, which must deal with the issue of the applicability of historical trends to future periods. The idea of this paper is to assess an approximate range for the involvement of technological alteration to growth in health spending, and to assess factors which might adjust this impact in the future. Based on the studies re-examined, we estimated that roughly half of growth in actual per capita health care costs is attributable to the beginning and diffusion of new medical technology, within an approximately probable range of 38 to 62 percent of expansion.
\end{abstract}

Keywords-medical technology; health costs; health care; research and development

\section{INTRODUCTION}

Doing research on medical technology for healthcare cost enhancement has always been a great mysterious. Yet 81 percent of the primary health economists agreed with the declaration, "The primary motive to increase in the health sector's share of gross domestic product (GDP) over the past 30 years is technological alteration in medicine"[1]. Evidently in most regions of the economy a rapid speed of technological progress is regarded as a good quality. This might not be the case for medical care where it reflects a second point of agreement.

In the past failing in medical care markets have failed to give incentives for the cost-effective condition of medical services, heartening the development and diffusion of improvement beyond the point that would overcome under spirited market conditions. Growing the role of technological change in driving growth in health spending, to the costs and benefits associated with new medical innovation reflects an acknowledgement of the long-term dilemma posed by historically unsustainable rates of growth in medical costs. It is combined with an increasing agreement that technological advance is a major factor in driving this growth. Understanding the magnitude of technology's historical contribution to growth in costs is very important to the analysis of the future path in medical spending.

Evaluation of macroeconomic approximations, it was considered that technological modifications accounted for around fifty percent (within a "probable" range of 38 to 62 percent) of growth in real per capita health expenses restricted on statements. However, even as we package that the increase of new medical technology is the most important factor in explaining the growth but important issues was as follow; first, a primary issue surrounding the rapid growth in health care costs is not the truth of such kind development but the possibility about reflecting an inefficient use of resources that would be more valuable to the society if applied somewhere else. To what level is spending on the growth and application of new technologies defensible by the paybacks? It conveys that research is beginning to attempt to value the benefits conveyed by new technologies. Detecting whether these returns have gone beyond approximated costs and to find out where the marginal profits of new expenses are possible to be the greatest. Second, to the extent that some expenses on innovative technologies is incompetent. How can the existing enticements be changed so as to motivate a more suitable reflection of cost effectiveness? The most important force to new research on these issues is recent rapid institutional change in the delivery of health services, particularly the rise of managed care. Resulting changes in incentives surrounding the development and introduction of new technology have the potential to alter both the future direction of medical innovation and the path of growth in health spending.

Our objective in this paper is to review an estimate of a probable range for the magnitude of the historical contribution in technological change to medical spending growth based on the body of existing macroeconomic, residual-based estimates, augmenting this work possibly based on additional research.

\section{MACRO-ECONOMIC EVALUATION: HOW SIGNIFICANT IS TECHNOLOGICAL ALTER?}

Health spending development has exceeded annual growth in GDP by an average of 2.2 percentage points for the period from 1940 through 1998; dynamically push the share of the economy's resources dedicated to health sharply upwards. The search for a justification of this strong-minded tendency has a correspondingly long history. While the expansion and diffusion of new medical technology has always been identified as an aspect in health expenses growth.

Expenses on innovative medical technology take account of growth associated with the development of diffusion of medical modernisms following their original introduction, to an objective of infiltration where no further distribution occurs in the deficiency of changes on other factors. Data considerations effectively prohibit the direct quantity of technology's role on aggregate health care expenses. Because of the approximations of the magnitude, the impact of technology health spending falls mainly into two categories. First, macro-economic estimates which relies on an indirect approach, trying to estimate the contribution of technology growth by considering the involvement of all other factors that control health spending. Second, educated guess based on analysis of the transform in behaviour patterns for an instance of patients over time which speaks to the impact of specific technologies particularly diagnoses within occurrences of care. Providing their focus on following the use of technology for residents of patients with a known diagnosis, these studies 
cannot confine the belongings of diffusion of new measures to broader populations. While such studies provide critical insights into the nature of technology's contribution to growth, a high degree of variability in the results across diagnosis and time period to rule out sweeping statement up to a level of agreement.

Evaluation of the involvement of technological change into cumulative growth must therefore rest primarily on studies based on the macro-economic residual approach, which provides the only comprehensive estimates of the contribution of technology to growth in the spending. However, a review of the methodology involved in the compilation of such estimates indicates that they must be applied with care. Any estimate based on the attribution of a residual after accounting for other factors will be sensitive to the identification of factors contributing to growth, as well as to the numerous assumptions necessary to evaluate the role of each factor. In addition, these estimates convey no information as to the nature of the process through which technology influences costs. One important objective of this review is to evaluate this sensitivity of residual-based estimates to the underlying assumptions, and the degree of uncertainty associated with each of the major assumptions. Based on this discussion, we produce our own estimate of the probable range for the contribution of technology to spending growth.

Ideally, macro-economic estimates of the residual growth attributable in technological change produce an estimate of the growth in health spending that would have occurred if medical technology had remained static. Suppose medical technology was frozen at a given point of time - what rate of growth in health spending would result from change in non-technology factors? Such factors include rising demand for medical services due to population growth and aging, the changing breadth and nature of health insurance coverage, rising real incomes, economy-wide inflation, and medical price inflation above economy-wide rates. Isolating the effects of technology requires that we appropriately and convincingly account for the contribution of all non-technology factors driving growth in health costs.

In calculating approximately the input of technological change by this system, our most important objective is to create a summary measure of the significance of technological change in explaining growth. However, in understanding the development through which this effect occurs, it is important to note that this contribution is dependent upon incentives inherent in financial and institutional structures within the health sector [2]. In addition to the scope that there are exchanges among the variables which power health spending growth, this methodology contains these effects in the approximate input of technological change as well. For instance, wide and more generous insurance coverage can be estimated to have significant effects on the development and dispersion of new medical technology [3].

\section{MACROECONOMIC RESIDUAL-BASED APPROXIMATIONS}

The corrosion of health expenses growth into factors accounting for development has long been utilized as a tool to assess the comparative importance of such factors. The beginning studies include Klarman, Rice, and Cooper (1970) and Freeland and Schendler (1983) [4]. However, the centre of these earlier studies was an accounting decay of the fraction of development attributable to power on growth such as economy-wide price rises, population growth, medical inflation and population aging. The result of behavioural factors contributing to grow in requirement for medical care was not addressed. It was known that the growth detained by the residual integrated the result of many different aspects; however, no effort was made to point the residual to the technology or to any grouping of other factors. Technological transform and the growing breadth and depth of insurance treatment promoted by tax-deductibility of the employeroffered health benefits were both found to play a most important role in the constantly rising share of GDP dedicated to health spending. However, estimates of the involvement of rising insurance coverage fluctuated by a factor of ten, permitting for the diligence of a broad range of positions. [5]

The present growing agreement that technological-alter is possiblly the important factor in describing health-spending growth constantly above GDP growth has set over the past many years. Much of these trends in thought replicate enhanced information on other significant factors contributing to the development. A foremost factor contributing to this trend was the accessibility of enhanced estimates for main parameters based on the consequences of the Rand Health Insurance Experiment (HIE), a randomized investigational study of the impact of insurance treatment on health expenses and composition at the family level. [6]

A second factor contributing to increase in health spending is growing real income which was also expected to account for only a small part of growth in real health expenditure. However, the income flexibility found by the HIE was somewhat small; richer family unit consumed only very slightly more medical care. The mass of the increase in real expenditure could not be described by either of these key factors. While the study does not afford to recognize all probable non-technology factors involved in growth, Manning et al (1987) concluded that the contribution of these two key factors is so little as to leave the large bulk of growth in real per capita health expenditure undescribed [6]. The authors hypothesized that technological change was the possible principal factor in describing the huge residual.

Current estimates try to identify systematically all behavioral factors offering to growth and to launch a fairly accurate magnitude for each. However, as told above, for some significant suppositions; there is yet no agreement. The position taken on key issues in the health economics literature (e.g. income elasticity of demand, comparative price changes in medical services) can outcome in broadly changing approximations of residual growth. We talk about the degree of hesitation linked with each of this hypothesis.

Two current studies, Newhouse (1992) and Cutler (1995) [7], [8], try a systematic decomposition of health expenditure development, expanding their estimates to integrate at least an estimated impact for all significant behavioural factors contributing to enlarge in health spending [8 ] [9]. Each of 
these studies admits the insecurity inherent in the residualbased methodology, specified the continuous lack of clear agreement on some of important parameters. For this reason, both papers bring to close rough estimates of the magnitude of technology's contribution for growth. Newhouse comes across that "(non-technology factors) account for well under half possibly under a quarter of the 50-years enhance in medical care spending", concluding, therefore that the residual onehalf to three-quarters of growth is attributable to the preface of new technologies [8]. Cutler tried to produce a lower bounce for technology's contribution, choosing the high end of his possible range for each non-technology factor. He concluded that a minimum of half the growth in real per capita expenditure for 1940-90 can be accredited to technological change [9].

\section{CONCLUSION}

Like innovations more commonly, procedures in medical technology help to advance our brilliance of life and provide citizens an advanced benchmark of living.

At an individual dealing level, advances in medical technology can make treatment less heavy or risky, and/or improve health outcomes, by rescheduling, reducing or getting rid of the need for further treatment. Few advances, such as going forward in e-health, improve efficiency and reduce errors. Lots of innovative programs make hospital treatment cheaper, because they minimize average length of staying life. However, because this will also free hospital beds, and because many modernizations also expand treatment frontiers, gains from any cost reductions tend to be put into additional treatments, at least in public hospitals, offsetting potential overall expenditure savings.

Moreover, some technological progresses are mainly cost increasing because they disclose completely new dealing frontiers, or because they are established with the aim of increasing patient safety or quality of care. These advances are occurring against a background of getting better overall health, but with the health enhancements being spreaded unevenly across the community. Technological advances can supply to reduce some of these inequities, such as the capability of telehealth and telemedicine to shrink the disadvantage in cost and access by knowledgeable people in rural and remote areas.

The interaction between increased levels of private health insurance with fast modernization in medical technology is possible to increase generally costs, and may increase access inequities. Current data point out that private patient treatment is around 25 per cent extra costly than municipal treatment, and that private patient expenses are rising twice as fast as public patient expenses.

Assessing the benefits and cost efficiency of technological progresses crosswise all health settings and conduct types is a most important challenge, and is the subject of significant attempt on the part of Government committees, researchers and clinicians. The different developments are not well incorporated and much greater teamwork between central and state governments is advantageous.

An incorporated national assessment development is the key to improve these processes and thus the efficiency and success of health expenses.

\section{ACKNOWLEDGEMENTS}

The authors acknowledge the continuous support of deanship of research in King Saud University since this research is funded by a grant from the deanship under the number of RGP - VPP - 150 .

\section{REFERENCES}

[1] Fuchs, V.R., "Economics, Values, and Health Care Reform", American Economic Review, 86:1-24, 1996.

[2] Weisbrod, B.A. "The Health Care Quadrilemma: An Essay on Technological Change, Insurance, Quality of Care, and Cost Containment, Journal of Economic Literature, June 1991, Vol. XXIX(2): 523-552.

[3] Peden, E.A. and Freeland, M.S. “An Analysis of Insurance Effects on

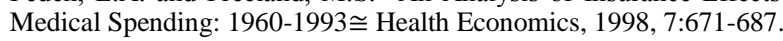

[4] Klarman, H.E., Rice, D.P., Cooper, B.S. Sources of Increase in Selected Medical Care Expenditures, 1929-1969, Social Security Administration, Office of Research and Statistics, Staff paper No. 4, April 1970.

[5] Freeland, M.S. and Schendler, C.E. "National Health Expenditures: Growth in the 1980's: An Aging Population, New Technologies, and Increasing Competition $\cong$ Health Care Financing Review, March 1983, Vol. 4(3):1-58.

[6] Manning, W.G., Newhouse, J.P., Duan, N., Keeler, E., Leibowitz, A., and Marquis, M.S., "Health Insurance and the Demand for Medical Care: Evidence from a Randomized Experiment", American Economic Review, Vol. 77, No.3, June 1987.

[7] Newhouse, J.P. "Medical Care Costs: How Much Welfare Loss?" Journal of Economic Perspectives, summer 1992, 6(3):3-21.

[8] Cutler, D.M. Technology, Health Costs, and the NIH, Harvard University and the National Bureau of Economic Research. Paper prepared for the National Institutes of Health Economics Roundtable on Biomedical Research, September 1995.

[9] Cutler, D.M. Technology, Health Costs, and the NIH, Harvard University and the National Bureau of Economic Research. Paper prepared for the National Institutes of Health Economics Roundtable on Biomedical Research, September 1995.

\section{AUTHORS PROFILE}

First Author was born on 5th Feb, 1978 at Kallanheri in Saharanpur district UP, India. He is working as a Researcher in College of Electronic Learning in King Saud University, Kingdom of Saudi Arabia. He received his Master of Science in Computer Science from Jamia Hamdard (Hamdard University), New Delhi, India in the year 2005, and PhD computer Science, C.S.J.M University Kanpur India. He is member of IEEE. He has actively attended many international conferences and published various research papers in National and International conferences as well as journals. His current areas of interests are in Cloud Computing, Software Engineering, Data Mining and E Learning. Apart from that he worked in the field of Software Development in different MNC companies at Noida India.

Second author was born in Kingdom of Saudi Arabia. He did Ph.D in Pharmacy from King Saud University in 2007. He chaired many position in the university and currently working as faculty member in pharmacy college affiliated to King Saud University. To date he taught nearly 280 pharmacy students, more than 30 courses. Students' level varies from primary to undergraduate levels Technology, USA and others. 